\title{
STYLOSA and FISTULATA: regulatory components of the homeotic control of
}

\section{Antirrhinum floral organogenesis}

\author{
Patrick Motte*, Heinz Saedler and Zsuzsanna Schwarz-Sommer† \\ Department of Molecular Plant Genetics, Max-Planck-Institut für Züchtungsforschung, Carl-von Linné-Weg 10, D-50829 KÖLN, \\ Germany \\ *Present address: Botany Department, University of Liège, B-4000 Liège, Sart-Tilman, Belgium \\ †Author for correspondence (e-mail: schwarzs@mpiz-koeln.mpg.de)
}

Accepted 20 October 1997; published on WWW 8 December 1997

\section{SUMMARY}

The identity and developmental pattern of the four organ types constituting the flower is governed by three developmental functions, $\mathrm{A}, \mathrm{B}$ and $\mathrm{C}$, which are defined by homeotic genes and established in two adjacent whorls. In this report we morphologically and genetically characterise mutants of two genes, STYLOSA (STY) and FISTULATA (FIS) which control floral homeotic meristem- and organidentity genes and developmental events in all floral whorls. The morphology of the reproductive organs in the first and second whorls of sty fis double mutant flowers indicate that the two genes are part of the mechanism to prevent ectopic expression of the $\mathrm{C}$-function in the perianth of wild-type flowers. This is verified by the detection of the expansion of the expression domain of the class C gene PLENA (PLE) towards the perianth. Interestingly, in the second whorl of sty and fis mutants, spatial differences in stamenoid features and in the pattern of ectopic expression of the $P L E$ gene were observed. This suggests that, with respect to the negative control of $P L E$, petals are composed of two regions, a lateral and a central one. Mutation in ple is epistatic to most of the sty/fis-related homeotic defects. $P L E$, however, is not the primary target of STY/FIS control, because dramatic reduction of expression of FIMBRIATA, meristem identity genes (FLORICAULA and SQUAMOSA) and of class $B$ organ identity genes (GLOBOSA) occur before changes in the $P L E$ expression pattern. We propose that STY/FIS are hierarchically high-ranking genes that control cadastral component(s) of the A-function. SQUAMOSA as a potential target of this control is discussed. Retarded growth of second whorl organs, subdivision of third whorl primordia and the failure to initiate them in sty/fis mutants may be mediated by the FIMBRIATA gene.

Key words: Flower development, Antirrhinum, Homeotic genes, Double mutants, STYLOSA, FISTULATA

\section{INTRODUCTION}

The identity of the four floral organs, sepals, petals, stamens and carpels, is governed by homeotic selector genes (Haughn and Somerville, 1988; Schwarz-Sommer et al., 1990; Coen and Meyerowitz, 1991). In the currently accepted model these genes fall into three classes (Okamuro et al., 1993; Weigel and Meyerowitz, 1994; Haughn et al., 1995), defining three developmental functions, $\mathrm{A}, \mathrm{B}$ and $\mathrm{C}$ that control alone and in combinations the developmental fate of organs. The A-function in the first whorl controls sepal identity and combined with B that of petals in the second; the $\mathrm{C}$-function alone controls carpel identity of fourth whorl organs and in combination with $\mathrm{B}$ the developmental fate of stamens in the third. The A, B and $\mathrm{C}$ functions in Arabidopsis were defined by loss-of-function mutants in homeotic genes, but only B- and C-type mutants were found in Antirrhinum (Schwarz-Sommer et al., 1990).

The control of floral organ identity in different species is similar in many respects. In particular, the class B and class C genes display structural and functional similarity (reviewed by Davies and Schwarz-Sommer, 1994). Their precise function and transcriptional control during flower development, however, may differ as shown by comparing class B genes of Antirrhinum and Arabidopsis (Samach et al., 1997).

The A-function in Arabidopsis includes two different levels of developmental control: that of organ identity by selection of the appropriate fate and the spatial (cadastral) restriction of the C-function to whorl 3 and 4. Mutants in class A genes may reveal both or only one of these functions. In addition, class A genes like $A P 1$ and $A P 2$ are involved in the control of the inflorescence to flower transition (Bowman et al., 1993; Jofuku et al., 1994). Recently, Okamuro et al. (1997) showed that the control of identity of perianth organs in ap 1 and ap 2 mutant flowers is likely to be linked to the role of these genes in the control of floral meristem identity rather than to a floral homeotic selector function.

There is little information concerning the A-function in Antirrhinum. The semidominant mutants Ovulata/Macho (Carpenter and Coen, 1990; Schwarz-Sommer et al., 1990; Coen and Meyerowitz, 1991) exhibit some of the morphological features of A-function mutants, indicating loss of a cadastral function that restricts $\mathrm{C}$ to whorls 3 and 4 . 
Ectopic expression of PLENA (PLE), a class C gene in this species, confirms this (Bradley et al., 1993). Ovulata/Macho are gain-of-function mutants; a transposon insert within an intron of the semidominant Ple allele allows PLE transcription in the perianth, without altering the structure of the mature $P L E$ mRNA (Bradley et al., 1993). A recessive loss-of-function mutant, representing the negative regulator of PLE, whose cisacting binding site may be corrupted in the Ple allele was not found. Here we describe recessive mutants of two genes, STYLOSA and FISTULATA, which together control the restriction of the $\mathrm{C}$ function to the inner whorls of the flower. Genetic, morphological and expression studies show, however, that $S T Y / F I S$ are more general regulators of homeotic functions in flower development.

\section{MATERIALS AND METHODS}

\section{Plant material and genetic stocks}

Antirrhinum majus plants were grown in the greenhouse at $18-25^{\circ} \mathrm{C}$ with additional light during winter. Some mutants and double mutants were transferred into climate chambers where they were grown at $15^{\circ} \mathrm{C}$ or $26^{\circ} \mathrm{C}$.

The wild-type line Sippe 50 and the stylosa (sty), fistulata (fis), fimbriata (fim) and deficiens-globifera (def-gli) mutants were obtained from the Gatersleben seed collection. The squamosa-347 (Huijser et al., 1992), plena-237 and Plena-888 (Macho; Schwarz-Sommer et al., 1990; Lönnig and Saedler, 1994) alleles were isolated in a transposon mutagenesis programme. The lines 165E (niv-98::Tam3) and T53 (niv-53::Tam1) were provided by Rosemary Carpenter (Norwich, UK).

The stylosa mutant (Stubbe, 1974) was crossed to different wildtype lines in order to analyse the extent of phenotypic variation. The $\mathrm{F}_{2}$ progeny consisted of both wild-type and sty plants that segregated in an approximately 3:1 ratio suggesting that the mutation is a single recessive trait. However, mutant plants were underrepresented in some populations. In the genetic background of Sippe 50 or T53, the sty phenotype was homogeneous. In the $165 \mathrm{E}$ background the floral morphology was variable and even a single inflorescence exhibited flowers with both weak and strong phenotypes. Variation in the floral phenotypes was sometimes acropetal, with old sty flowers showing a weak, sometimes almost wild-type phenotype, and young flowers displaying strong morphological abnormalities. Since we found no heritable traits influencing the sty phenotype, it is likely that this variability reflects changes in environmental conditions and/or a gradient of some internal factors within the inflorescence.

\section{Double mutants}

Double mutants between sty and other floral homeotic mutants were identified in $\mathrm{F}_{2}$ populations as plants displaying floral features not observed in the single mutants. Genetic constitution of sty fis, sty Ple888 and sty fim double mutant plants was confirmed by test crosses. Sty def double mutants were identified by analysing the segregation ratio.

Double and triple mutant combinations of sty and fis with ple display subtle morphological differences compared to ple. Reduced fertility of sty and sterility of ple made it impossible to obtain larger number of double and triple mutants by selfing plants homozygous for one trait and heterozygous for the other. The ple-237 allele, in addition, showed increased somatic instability in the background of the fis mutation providing us with easily selectable fis ple double mutants, or sty fis ple triple mutants (after selfing of fis plants heterozygous for ple and sty). The occurrence of such double mutants indicates that the STY, FIS and $P L E$ loci are not tightly linked genetically.

\section{Microscopy and in situ hybridisation}

For scanning electron microscopy (SEM), inflorescences were processed as described previously (Sommer et al., 1990). Tissue preparation and in situ hybridisation experiments were carried out

Table 1. Homeotic morphology displayed by different mutants

\begin{tabular}{|c|c|c|c|c|c|c|c|c|c|}
\hline \multirow[b]{2}{*}{ Wild type } & \multirow[b]{2}{*}{$\begin{array}{l}\text { Upper } \\
\text { leaves }\end{array}$} & \multirow[b]{2}{*}{ Bracts } & \multicolumn{3}{|c|}{ Whorl 1p } & \multicolumn{2}{|c|}{ Whorl $2^{p}$} & \multirow{2}{*}{$\begin{array}{l}\text { Whorl } 3 \\
\text { Stamens }\end{array}$} & \multirow{2}{*}{$\begin{array}{c}\text { Whorl } 4 \\
\text { Gynoecium }\end{array}$} \\
\hline & & & $\begin{array}{c}\text { Abaxial } \\
\text { sepals (2) }\end{array}$ & $\begin{array}{c}\text { Lateral } \\
\text { sepals (2) }\end{array}$ & $\begin{array}{l}\text { Adaxial } \\
\text { sepal (1) }\end{array}$ & $\begin{array}{l}\text { Abaxial } \\
\text { petals (3) }\end{array}$ & $\begin{array}{l}\text { Adaxial } \\
\text { petals (2) }\end{array}$ & & \\
\hline stylosa & - & - & $\{$ petaloid $\}$ & $\{$ petaloid $\}$ & - & stamenoid & retarded* & $\begin{array}{l}\text { stamenoid/carpelloid, } \\
\text { subdivided }\end{array}$ & + \\
\hline fistulata & - & - & - & - & - & stamenoid & retarded $*$ & - & - \\
\hline sty fis & - & - & carpelloid & carpelloid & - & $\begin{array}{l}\text { stamenoid/ } \\
\text { carpelloid, } \\
\text { arrested }\end{array}$ & arrested $^{\mathrm{u}}$ & $\begin{array}{l}\text { stamenoid/carpelloid, } \\
\text { missing/subdivided }\end{array}$ & + \\
\hline Macho & - & carpelloid* & carpelloid & carpelloid & carpelloid & stamenoid & retarded & - & - \\
\hline sty Macho & carpelloid & carpelloid $^{\mathrm{u}}$ & carpelloid ${ }^{\mathrm{u}}$ & carpelloid $^{\mathrm{u}}$ & carpelloid $^{\mathrm{u}}$ & $\begin{array}{l}\text { stamenoid/ } \\
\text { carpelloid, } \\
\text { arrested } *\end{array}$ & arrested $^{\mathrm{u}}$ & $\begin{array}{l}\text { stamenoid/carpelloid, } \\
\text { subdivided }\end{array}$ & + \\
\hline ple & - & - & - & - & - & - & - & petaloid & $\begin{array}{l}\text { carpelloid/sepaloid/ } \\
\text { petaloid, } \\
\text { indeterminate }\end{array}$ \\
\hline sty fis ple & - & - & - & - & - & retarded & retarded ${ }^{\mathrm{u}}$ & petaloid, subdivided & ple-like \\
\hline def & - & - & - & - & - & sepaloid & sepaloid & carpelloid & absent \\
\hline sty def & - & - & - & - & - & carpelloid, + & carpelloid, + & carpelloid $^{\mathrm{u}},+$ & + , locules \\
\hline fim & - & - & - & - & - & $\begin{array}{l}\text { petaloid/ } \\
\text { sepaloid }\end{array}$ & $\begin{array}{l}\text { petaloid/ } \\
\text { sepaloid }\end{array}$ & \{petaloid/carpelloid\} & short style \\
\hline sty fim & - & - & - & - & - & $\begin{array}{l}\text { stamenoid/ } \\
\text { carpelloid }\end{array}$ & retarded* & carpelloid $^{\mathrm{u}}$ & + \\
\hline
\end{tabular}

pDifferences observed in features of abaxial and adaxial organs may be due to the function of genes determining the symmetry of the flower and are not

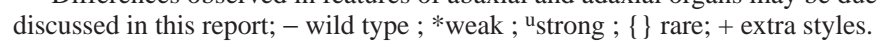


according to published procedures (Coen et al., 1990; Huijser et al., 1992). As a control, sections of wild-type buds were placed side by side with mutant sections.

\section{RESULTS}

Wild-type flowers have previously been described in detail (Schwarz-Sommer et al., 1992). Briefly, the perianth consists of two abaxial, two lateral and one adaxial sepals in the first whorl forming the calyx and five petals in the second whorl forming the corolla with two adaxial and three abaxial lobes. The third whorl is composed of four stamens and the stamenodium. The gynoecium is formed by fusion of two carpels in the centre of the flower.

In most mutants and mutant combinations described below, morphological anomalies differ in abaxial and adaxial organs (Table 1), perhaps due to combinatorial effects with genes involved in the control of the symmetry of the flower. Detailed description and discussion of these features are not the subject of this report.

\section{Morphology of sty flowers}

The stylosa mutation does not affect vegetative parts of the plant but causes complex floral homeotic organ alterations. The morphology of sepals is usually normal, except that sometimes they appear petaloid along their margins (Fig. 1A and Table 1).

In mature sty flowers petal morphology is distorted. The organs are reduced in size, or retarded in growth and are sometimes twisted (Fig. 1A,B). The marginal region of petals may display morphological features of stamens with filamentlike structure at their base and along the tube and an antherlike structure at the upper part (Fig. 1A,B). Complete transformation of petals into stamens was not observed.

The third whorl organs are feminised. However, both the number of feminised stamens and the degree of feminisation are variable. In the most frequent intermediate phenotype, individual organs display combined stamenoid and carpelloid identities. Some of the feminised stamens fuse to the fourth whorl, resulting in a complex chimeric structure in the centre of the flower (Figs $1 \mathrm{C}$ and $2 \mathrm{G}, \mathrm{H}$ ). The number of third whorl organs seems to be increased, although the number of third whorl primordia is not affected (see below). In the strongest phenotype, third whorl organs are almost completely carpelloid and show little stamen identity. In the weakest phenotype only abaxial third whorl organ number seems to be increased (Fig. 1D). The shape of anthers is abnormal and a short style sometimes develops at the tip (not shown). Due to feminisation of stamens the male fertility of sty flowers is reduced.
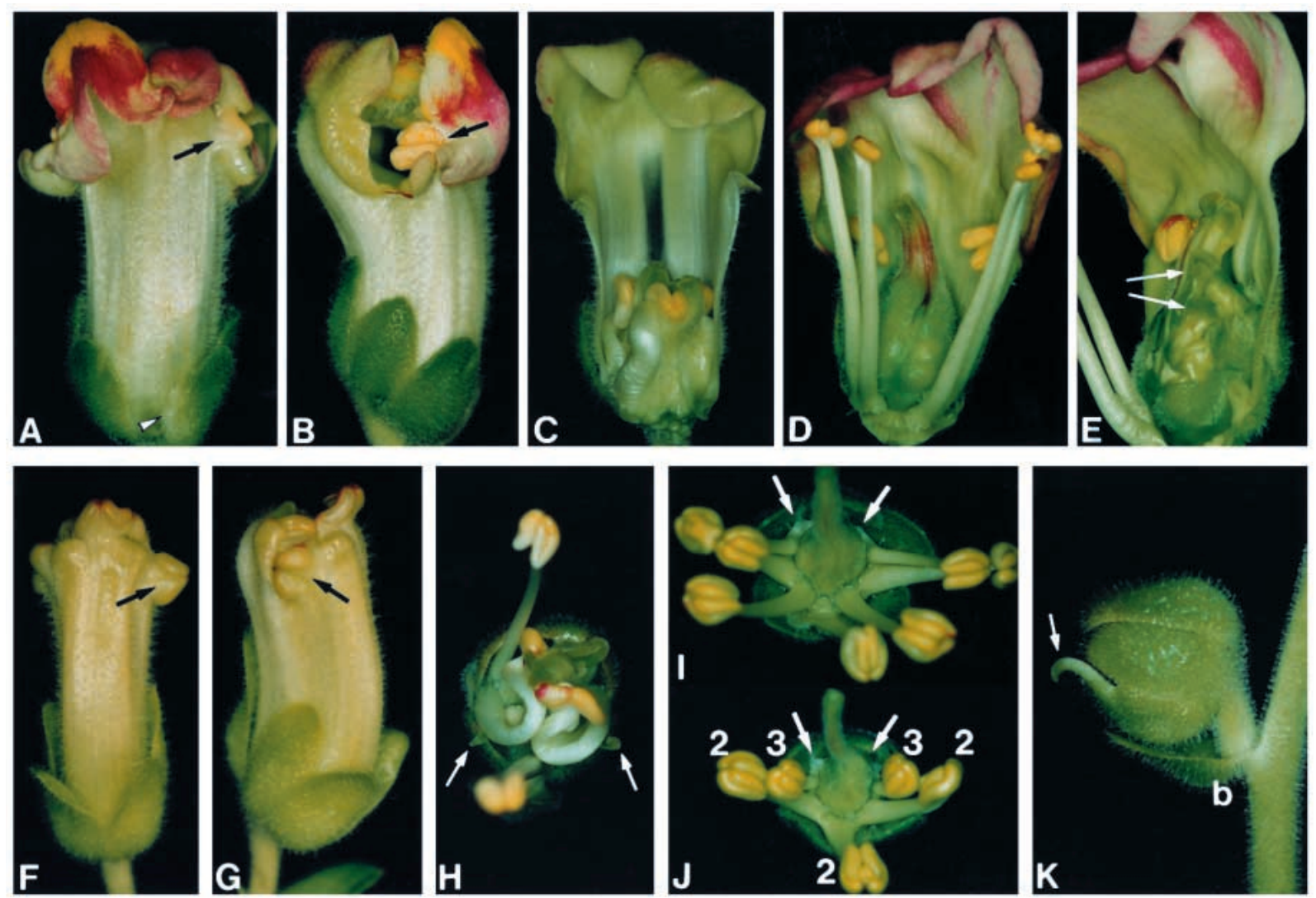

Fig. 1. Phenotypes of mature sty (A-E), fis (F,G) and sty fis mutant (H-K) Antirrhinum flowers. A and C-F show flowers in a ventral view; B and $\mathrm{G}$, lateral view and in H-J, top view. Abaxial sepals and petals are removed to show the complex chimeric structure due to fusion of feminised stamens with the gynoecium (C,D) and the style-like outgrowths inside the carpels (arrows in E). Black arrows in A,B,F and G point to stamenoid second whorl organs and the arrowhead in A points to a petaloid sector of the abaxial sepal. The white arrows in $\mathrm{H}$ and $\mathrm{K}$ show first whorl organs with carpelloid features and indicate positions of the arrested second whorl organs in I and J. In J the numbers indicate the position of the stamens in whorl 2 and 3. 
The sty mutation most severely affects development of the gynoecium. The carpel and the style may be shorter and broader than in the wild type (Fig. 1D). The two carpels sometimes fail to fuse. In all types of sty flowers, thin or broad style-like structures with stigmatic papillae are visible inside the fourth whorl (Fig. 1E). The origin of these structures is not clear, but it is likely that they develop from the placenta or from the receptacle rather than from homeotically altered ovules. The number of these style-like structures and the extent of their growth are variable. In extreme cases, style-like outgrowths confer such a high physical tension to the inner surface of the carpel that it bursts. Although carpels contain welldifferentiated ovules the female fertility of sty flowers is reduced or completely abolished.

\section{Ontogeny of sty flowers}

Inflorescences were examined by SEM to determine at which stage floral organogenesis of sty mutants deviates from wild type. The developmental pattern of sty floral meristems does not differ from wild type until after stage 5 (petal mound; Carpenter et al., 1995) when the five sepal primordia are well separated and start to overgrow the floral meristem. At this stage, as in the wild type, five petal primordia initiate at alternate positions with respect to the sepals and four stamen primordia start to initiate at positions alternate to petal primordia (compare Fig. 2A with Fig. 2E). Retardation of second whorl organ development is visible after stage 6 (Fig. $2 \mathrm{G}, \mathrm{H})$.

Third whorl primordia subdivide and grow as two instead of one organ soon after initiation (Fig. 2F). Thus, the increased number of third whorl organs in mature flowers correlates to subdivisions of primordia and not to initiation of additional primordia. In flowers with intermediate phenotype all third whorl primordia become subdivided, resulting in several filamentous outgrowths. Concomitantly, stamens undergo homeotic alterations and differentiate into stamen-carpel chimeric structures. Feminised third whorl primordia invade the centre of the meristem where they fuse with the developing gynoecium (Fig. 2G).

\section{Morphology and ontogeny of fis flowers}

Fis mutant plants and double mutant combinations with fis
Fig. 2. SEM showing the ontogeny of wild-type (A-D), sty (E-H), fis (I-L) and sty fis (M-T) mutant flowers. (A,E,I,M) Inflorescences with developing young flowers at different stages of development. Arrowheads point to flowers at stage 5 (Carpenter et al., 1995). (B,F,J,N) Flowers at stage 6 . The genotype of plants is indicated at the left of the rows. Asterisks show the adaxial position within the flower and numbers indicate the position of organs in the floral whorls. The arrow in $\mathrm{F}$ points to a subdivision characteristic for third whorl organs of sty and the arrow in G shows the fusion of the subdivided third whorl organs to the fourth whorl. The flower in $\mathrm{H}$ reveals this fusion together with suppression of petals and abnormal anthers. (J) fis flowers are morphologically similar to wild type until stage 6 and morphological differentiation of lower petal lobes into antheroid structures is apparent after stage $6(\mathrm{~K})$. (L) Suppression of adaxial lobes and fusion of the corolla tube. (M) a sty fis flower displays irregularly formed sepals at early stage 5 . (N) Notice initiation of five second whorl organs and further development of second whorl organs with fusion between second and third whorl organs. $\mathrm{O}$ and $\mathrm{P}$ demonstrate the absence of third whorl organ initiation (empty space between the two second whorl organs designated by black $2 \mathrm{~s}$ ) and arrested development of lateral second whorl organs (white arrow), respectively. Q shows a less extreme phenotype with suppression of adaxial petals, complete homeotic transformation of abaxial petals into stamens and absence of a corolla. If they develop, second whorl organs can become carpelloid and fuse to the gynoecium (R). $\mathrm{S}$ and $\mathrm{T}$ show the degree of homeotic sepal transformations of plants grown at $15^{\circ} \mathrm{C}(\mathrm{S})$ or at $25^{\circ} \mathrm{C}$ ( $\mathrm{T}$, arrow points to ovules). The bars represent $100 \mu \mathrm{m}$ except in Q, R and T where they are $500 \mu \mathrm{m}$.
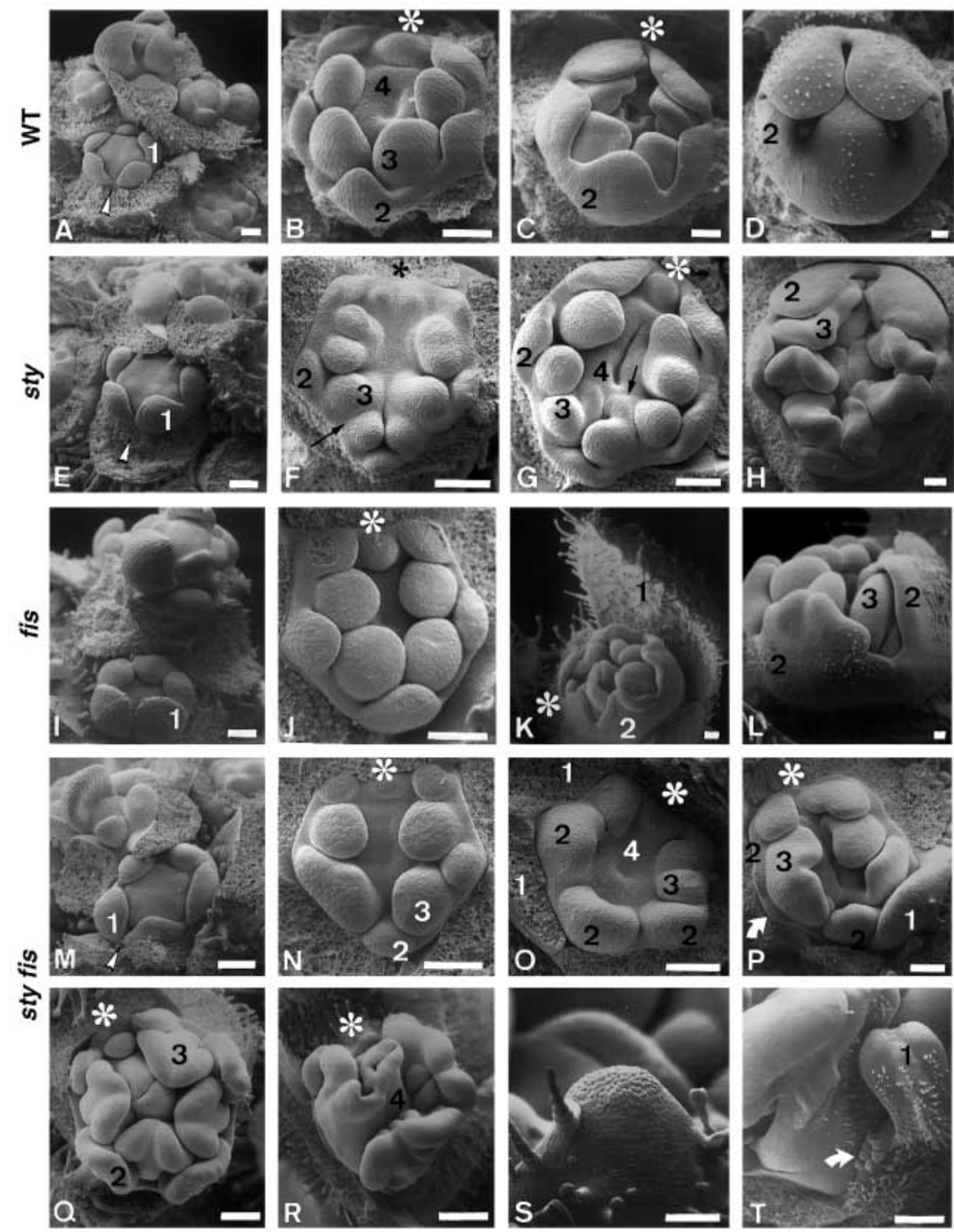
were only analysed as far as was necessary to understand the interaction of FIS with STY. Fis petals are frequently transformed into stamenoid structures or their development is retarded (Fig. 1F,G). The lower part of the petals still forms a corolla tube but their upper part does not display typical lobes. Instead, the tips of the 3 abaxial petals often bear anther-like and male fertile structures. SEM analysis showed that homeotic transformation of petals occurs late, after stage 6 of development (Fig. 2J,K). It also confirmed that sepals, stamens and the gynoecium are not affected homeotically (Fig. 2I,K). Homeotic transformation of fis second whorl petals strongly resembles the blind mutant in petunia in that mainly the lobes are transformed into a stamenoid structure (Tsuchimoto et al., 1993). Blind mutants display weak carpelloidy of sepals, a feature occasionally apparent in the first whorl of fis-2, a newly isolated fis allele (Z. Schwarz-Sommer and E. de Andrade Silva, unpublished).

The stamenoid features of second whorl organs can increase or decrease in different backgrounds, depending on the presence or absence of modifying factors (I. Heidmann and Z. Schwarz-Sommer, unpublished data). Fis sister plants in the $\mathrm{F}_{2}$ population (necessary to obtain double mutants with sty) displayed the uniform intermediate phenotype shown in Figs 1 and 2.

\section{Double mutant analysis}

Double mutants were constructed to uncover interactions between STY and genes controlling flower development. Phenotypic differences between wild-type and mutant flowers are summarised in Table 1.

\section{stylosa/fistulata}

The sty fis double mutant combination severely affects all four whorls (Figs 1H-K, 2M-T and Table 1). The sepals of sty fis flowers are carpelloid with some variability depending on growth conditions. Plants grown at $26^{\circ} \mathrm{C}$ display strong carpelloidy of sepals with ovules developing along their margins (Fig. 2T). Carpelloidy of sepals is less pronounced at $15^{\circ} \mathrm{C}$, where stigmatic papillae may develop at the tips of the organs (Fig. 2S).

The second whorl of sty fis flowers shows transformation of the abaxial petals into stamens. The organs are either composed of carpelloid stamens fused to the third whorl organs (Fig. 1H) or of narrow filaments and anthers resembling wild-type stamens (Figs 1I,J and 2Q). Adaxial petals do not develop (arrows in Fig. 1I,J) or, at $26^{\circ} \mathrm{C}$, develop into aborted stamens or into short and narrow petaloid filaments.

Similar to sty single mutants, third whorl organs of sty fis flowers exhibit different phenotypes under greenhouse conditions. In one type of sty fis flowers, carpelloid stamens that may be fused to the gynoecium are present (Figs $1 \mathrm{H}$ and 2Q) and in the other type the organs show no severe feminisation (Fig. 1I,J). However, growth at $26^{\circ} \mathrm{C}$ facilitates feminisation of second and third whorl organs and their fusion to the fourth whorl. In both phenotypes, the total number of second and third whorl stamens is often reduced, but in the mature flower it is not always clear which stamen, in which whorl, is absent. SEM analysis showed that arrest of second whorl organ development occurs subsequent to organ initiation while sometimes third whorl organs are not initiated (Fig. 2O,P). SEM studies also revealed complex fusion between second and third and third and fourth whorl organs (Fig. 2P,R) as well as carpelloidy of the first whorl sepals (Fig. 2S,T).

Features displayed in sty fis flowers not observed in the single mutants, such as carpelloidy of sepals or the reduced number of third whorl organs, indicate synergistic interaction between the two genes.

In summary, sty fis flower morphology resembles that of the Arabidopsis A-function mutants ap2 (Jofuku et al., 1994) and apl (Schultz and Haughn, 1993), in all homeotic organ type alterations. However, floral identity of organs in the first whorl is not affected and perianth organ number is not reduced. The similarity to mutants like lug (Liu and Meyerowitz, 1995) and clf (Goodrich et al., 1997) is also incomplete: sty fis does not affect leaf morphology, and lug and clf flowers do not display feminised features in their second or third whorl organs.

The phenotypic similarity of sty/fis and mutants of the Arabidopsis A class gene AP2, prompted us to clone Antirrhinum cDNAs which display sequence similarity to AP2 (H. Sommer, P. Motte, H. Meijer, Z. Schwarz-Sommer, unpublished). RT-PCR and northern blot experiments failed to show alteration of expression of these genes in fis or sty mutants (not shown). Thus the structural similarity of the STY or FIS genes with AP2 remains an open question.

\section{stylosa/plena}

The morphology of sty, fis and sty fis mutants indicates ectopic expression of the $\mathrm{C}$-function in the two outer whorls. Double mutants were constructed with ple to determine if mutation in this class $\mathrm{C}$ gene is epistatic to sty or fis. In the recessive plena mutant the first and second whorls appear normal, while the stamens are petaloid narrow organs and often fuse to the second whorl (Fig. 3A,D). The two fourth whorl organs display a combination of sepaloid, carpelloid and petaloid features. Inside, a new flower with petaloid and sepaloid organs develop (Bradley et al., 1993). In the $\mathrm{F}_{2}$ populations only wild-type, sty and ple phenotypes appeared, suggesting that ple is epistatic to sty. On some of the ple plants, flowers displayed additional abaxial petaloid organs adjacent to the third whorl organs, resembling subdivision of third whorl organs in the sty mutant (Fig. 3E).

In the $\mathrm{F}_{2}$ population, developed to obtain fis ple double mutants, frequent somatic reversion of the genetically unstable ple-237 allele occurred, making determination of the fis ple phenotype difficult. Among non-reverting ple flowers some displayed slightly retarded development of second whorl petals. Interestingly, due to partial somatic reversion of ple, some fis ple double mutants with partially restored stamens still display indeterminacy (Fig. 3C,F). The petaloid organs internal to the fourth whorl are stamenoid, suggesting that restoration of the PLE function in the centre of the flower is sufficient to confer fis-dependent stamenoidy to the petaloid organs, while it is insufficient to prevent indeterminacy (Fig. 3F).

The sty fis ple triple mutant was obtained in the progeny of a selfed fis plant that was heterozygous for sty and ple. Among 32 ple plants, some of which displayed the features of ple sty or ple fis double mutants mentioned above, two plants with unusual morphology were found. The genetic constitution of the triple mutant was confirmed by examining in situ expression patterns of genes that are severely affected in the sty fis double mutant (see below). In their third whorl the triple mutants exhibit slightly increased petaloidy compared to ple 

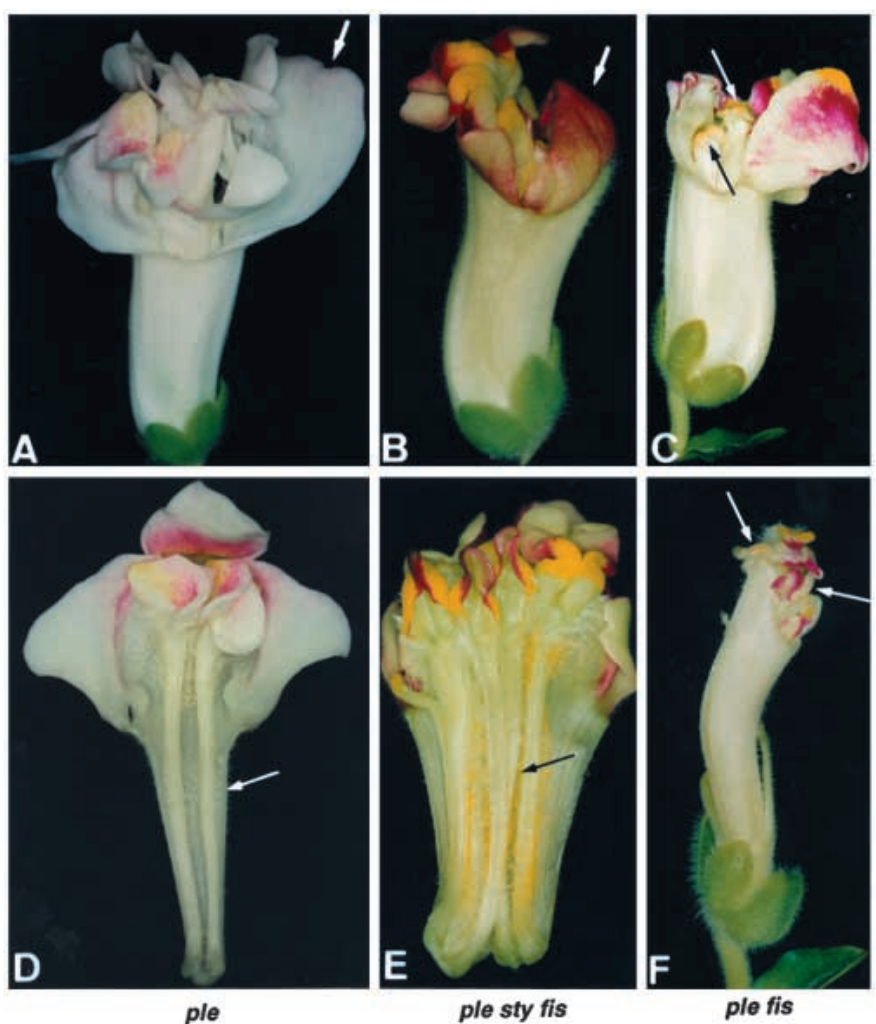

Fig. 3. Phenotype of ple (A,D), sty fis ple (B,E) and ple fis $(\mathrm{C}, \mathrm{F})$ flowers obtained in a population segregating for the ple, sty and fis mutants. Intact flowers in the top row are shown in a lateral view. Arrows in A and B point to the adaxial lobe of the corolla which is severely reduced in the triple mutant (B). D and E show the morphology of abaxial petaloid third whorl organs (fused to the abaxial lobe and indicated by arrows) after removing the adaxial part of the flower. Notice the complex, subdivided third whorl organs in $\mathrm{E}$ compared to the simple petaloid stamens in D. The ple fis flower in C (lateral view) and F (second and third whorl organs removed) displays partial somatic reversion of the ple-237 allele, revealed by restoration of stamens (arrows in $\mathrm{C}$ ) and indeterminacy combined with development of stamenoid petals (arrows in F) in the centre of the flower.

mutants, and split organs similar to subdivisions in ple sty flowers (Fig. 3). Second whorl upper and lower lobes are severely suppressed (Fig. 3B). These observations suggest that ple is epistatic to sty and fis with respect to homeotic organ transformations, but the STY and FIS functions are independent of PLE expression with respect to retardation of development of the second whorl and possibly to subdivisions in the third whorl.

The double mutant, sty Ple-888 (Lönnig and Saedler, 1994) was constructed to determine whether structural alteration of the semidominant Ple allele (see Introduction) renders its expression independent of $S T Y$. In our $\mathrm{F}_{2}$ populations developed to generate double mutants with sty, Ple-888 sister plants showed five carpelloid sepals with or without ovules. Adaxial second whorl organs appeared as narrow, split petaloid structures, retarded and sometimes arrested in development, similar to the stamenodium in the third whorl of wild-type flowers. The three abaxial petaloid organs often displayed antheroid features. Female fertility of Ple-888 flowers is frequently reduced. Upper leaves were not affected by the mutation.

Sty in an either homo- or heterozygous Ple-888 background conditions strong homeotic transformation of the youngest leaves subtending the inflorescence, into carpelloid leaves with stigmatic tissue at their tips (Fig. 4A,B). This homeotic transformation of the upper leaves facilitated selection of double mutants. The bracts subtending the floral meristems also display strong carpelloidy. In double mutants, in contrast to wild-type and Ple- 888 inflorescences, the carpelloid bracts do not overgrow the apical meristem which remains visible for a long period of development (Figs 4B and 5A). The aberrant morphology of bracts and upper vegetative organs uncovers functions of the $S T Y$ gene outside the flower.

Within the flower, first whorl organs may fuse laterally due to increased carpelloidy of the sepals. The second whorl organs either develop as (carpelloid) stamens without petaloid sectors (Fig. 4C,D) or are arrested in development and abort (Fig. 5C and Table 1). The stamenoid-carpelloid third whorl primordia subdivide as in sty flowers (Fig. 5B) and can fuse to the gynoecium and to the sometimes feminised second whorl stamens. Because of such fusions it is difficult to determine the origin of organs in mature flowers. Complete transformation of the stamenodium into a small individual ovule-containing carpel may also occur. In extreme cases, floral organs in all whorls display strong carpelloidy and little or no stamenoid features Fig. 5D). Increased severity of the Ple- 888 mutant phenotype including carpelloidy of non-floral organs by combination with sty indicates that the structural alteration of the PLE gene in the Ple- 888 allele does not prevent control events governed by $S T Y$.

\section{stylosa/deficiens}

The null allele def-gli confers sepaloidy to petals and carpelloidy to stamens (Sommer et al., 1990; Schwarz-Sommer et al., 1992). Sty def double mutant flowers exhibit a first whorl of five wild-type-like sepals with no morphological alterations. The sepaloid second whorl organs are feminised. Their margins are carpelloid and may bear ovules and their tips are stigmatic (Figs 4E,F and 5H). Carpelloidy of second whorl organs in the absence of $D E F$ function confirms stamenoidy of petals in the sty mutant. The margins of second whorl organs can fuse to the third whorl. Sometimes second whorl carpelloid sepals become incorporated into the third whorl and grow as a broad individual organ. Such a fusion is most frequent between one pair of organs but several fusions are also possible (Fig. 5G). SEM analysis showed that the four carpelloid third whorl organs initiate at the correct position and correct time, although early fusion between the margins of the second and third whorl organs may result from a slight displacement of primordia conditioning spiral rather than whorled arrangement of organs (Fig. 5G). Style-like outgrowths, characteristic of the fourth whorl carpels of sty flowers can differentiate in all carpelloid organs of sty def flowers (Fig. 4F). Subdivision of third whorl primordia similar to that of sty flowers cannot be observed (Fig. 5E,F). Interestingly, additional locules develop inside the third whorl of sty def flowers (Fig. 4I), where no organs develop in def-gli flowers, reminiscent of fim def double mutant morphology (Tröbner et al., 1992). The reason for this feature is not clear. 

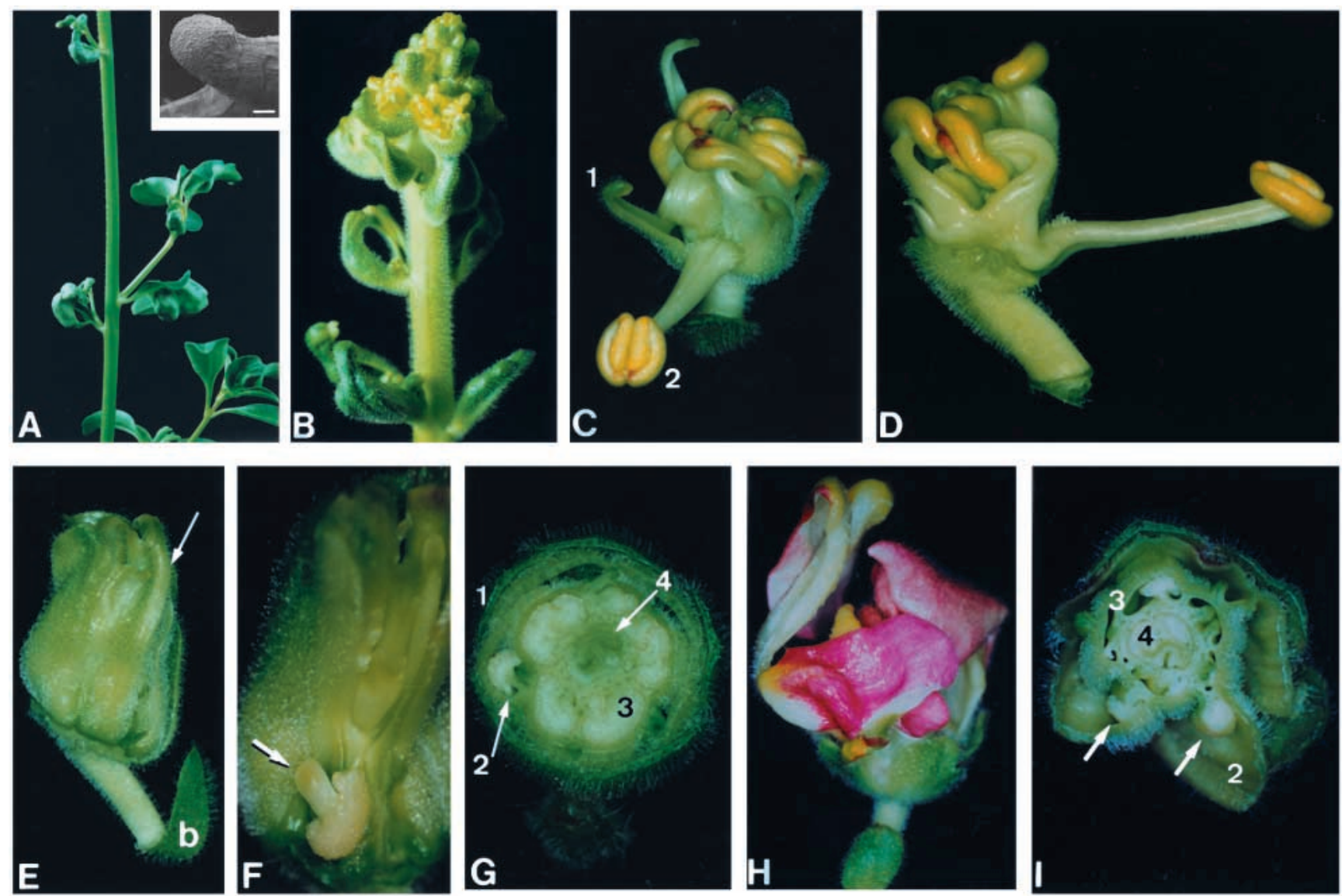

Fig. 4. Phenotypes of sty Ple-888 (A-D), sty def (E-G) and sty fim (H,I) double mutants. The upper leaves below the inflorescence of sty Ple-888 mutants are curly and the SEM demonstrates stigmatic papillae at their tips (A; bar $=100 \mu \mathrm{m})$. The bracts are strongly carpelloid (B). (C) Frontal and (D) lateral views of a mature floral bud with carpelloid sepals (1) in the first whorl and morphologically wild-type or carpelloid stamens (2) in the second. (E) Lateral view of the interior of a sty def bud with carpelloid second whorl margins (arrow; b, bract). Ovules adjacent to a stylelike structure (arrow) can develop at the fusion between carpelloid second whorl sepals and third whorl organs (F). This is also visible in the cross-section in G (2) as well as additional locules internal to third whorl organs (4). (H) A sty fim flower in frontal view. Complete homeotic transformation of stamens into carpels and their fusion to the fourth whorl is clear in the cross-section in I. Carpelloidy of the margins of petaloid organs and their fusion to the third whorl where ovules differentiate is also visible (arrows). Floral whorls are indicated by numbers.

\section{stylosa /fimbriata}

Fim flowers display homeotic organ alterations in whorls 2, 3 and 4 and the extent of these alterations differs in different fim alleles (Simon et al., 1994). In the analysed $F_{2}$ population the petals of fim flowers showed streaks of green sepaloid tissue, the stamens were wild-type-like, or slightly petaloid to carpelloid and the organs sometimes fused to the gynoecium. The gynoecium was either wild-type-like or displayed a short style and reduced female fertility. The fim mutation in this population most strongly affects establishment of the Bfunction.

In sty fim double mutant flowers (Figs 4H,I and 5I-L) organ differentiation in the second whorl is complex. In the mature flower, petals contain sepaloid sectors, they are not fused and the abaxial organs display stamenoid and/or carpelloid features. A filament and an antheroid structure can develop at the margin of some of the second whorl organs (Fig. 5L). The four stamens and the stamenodium in the third whorl are transformed into carpelloid organs (Figs 4I and 5J,K). Second and third whorl organs can fuse and along this fusion ovules develop (arrows in Fig. 4I). SEM uncovers early fusion of second whorl organs with a third whorl carpel (Fig. 5J) similar to the spiral pattern described for stronger fim alleles (Ingram et al., 1997) and sty def flowers. The subdivision of third whorl organs, typical for sty flowers, does not occur. In this respect fim seems to be epistatic to sty, while the two genes act synergistically concerning homeotic effects related to decrease of the B-function.

\section{In situ hybridisation}

In situ mRNA hybridisation experiments were carried out using probes for meristem identity genes, FIM and organ identity genes to determine more precisely the role of STY and FIS in the spatial and temporal control of homeotic gene expression.

\section{Expression of meristem identity genes}

In the bracts and in very young floral meristems of wild type, sty, and fis mutants SQUA (Huijser et al., 1992) is uniformly expressed at high level (Fig. 6A,B,D). During organ initiation $S Q U A$ expression in the wild type and in the mutants becomes restricted to first and second whorl organs. At stages 4 to 5 SQUA transcription in sty sepals and petals starts to be slightly 
Fig. 5. SEM of developing flowers of sty Ple-888 (A-D), sty def (E-H) and sty fim (I-L) double mutants. The sty Ple-888 inflorescence in A shows strong carpelloidy of bracts that fuse to each other and do not cover the apical meristem. In B a stage 6 flower is shown with

subdivisions of abaxial stamens. Extreme phenotypes are depicted in $\mathrm{C}$ and $\mathrm{D}$, with retarded second whorl development (arrow) or homeotic transformation of petals into carpelloid organs (arrowhead in C). $\mathrm{E}$ and $\mathrm{F}$ show initiation of third whorl primordia at the correct position and the absence of their subdivision in sty def mutants. In G fusion of the margins of some second whorl organs with carpelloid third whorl organs confers spiral arrangement of second and third whorl organs. (H) A close-up of differentiating ovules at the fusion between second and third whorl organs. Sty fim flowers display homeotic transformation at the margin of second whorl organs at early stage $5(\mathrm{I})$ and $6(\mathrm{~J})$, but

subdivision of third whorl organs is absent $(\mathrm{J}, \mathrm{K})$. (L) The margins of a sty fim second whorl organ differentiate into stamenoid (arrow) and carpelloid (arrowhead) tissues. Numbers indicate the respective floral whorls. Bars represent $100 \mu \mathrm{m}$; except in A and L, $500 \mu \mathrm{m}$.
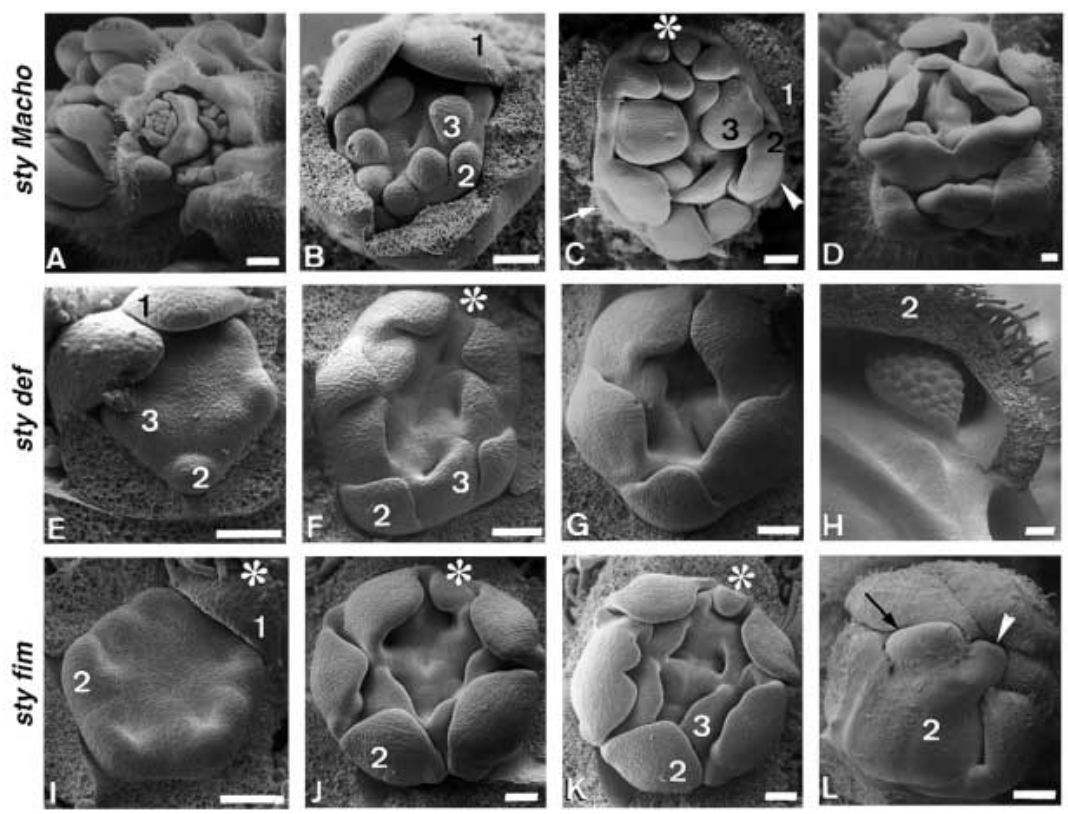

reduced as compared to wild type (Fig. 6B,E,F) and decreases more strongly during later stages (not shown). This observation suggests that $S T Y$ is necessary to maintain $S Q U A$ transcription.

In sty fis double mutants $S Q U A$ expression is similar to wild type until stage 3 (Fig. 6C). Subsequently the transcript level is severely reduced in the entire young flower including sepals and in initiating second whorl organs (Fig. 6G). SQUA transcripts are present until stages 4 to 5 in sepals and in the cells giving rise to second whorl organs, but the amount is low such that undiluted emulsion and longer exposure time had to be used for detection (not shown). Later SQUA transcripts disappear in sepals and in arrested second whorl organs (Fig. $6 \mathrm{H})$. During late stages of development $S Q U A$ expression reappears in the fourth whorl of wild-type, sty and fis flowers within the carpel wall facing the placenta, and also at reduced levels in the sty fis double mutant (Fig. 6H). Decrease in early SQUA expression in sty fis ple flowers is similar to sty fis flowers, confirming the genetic constitution of the triple mutant (not shown).

Interestingly, in the second whorl organs of fis flowers at stage 6, and later, SQUA expression is only detectable in those regions that do not undergo homeotic organ transformation (Fig. 6I). This resembles the reduction of SQUA expression in wild-type stamens (Huijser et al., 1992) and suggests that late reduction of SQUA transcription is concomitant with stamen development, irrespective of the position of the organ.
Fig. 6. In situ expression pattern of SQUA in wild-type (A), sty (B,E), fis (D,I) and sty fis $(\mathrm{C}, \mathrm{G}, \mathrm{H})$ mutants. Longitudinal sections of inflorescences (A-D) and flowers (E-I) were hybridised with the ${ }^{35} \mathrm{~S}$-labelled antisense RNA probe. The hybridisation signal was photographed in dark-field, superimposed on the epifluorescence exposure. The oldest flower shown in $\mathrm{A}$ is at about stage 5; those in $\mathrm{B}$ and $\mathrm{D}$ are at stage 4 (right) and 6 (left) and those in D at stage 4 (right) and about 6 (left). (F) An epifluorescence photograph of $\mathrm{E}$ to demonstrate uniform decrease in SQUA expression in stage 5 sty flowers in the entire floral meristem including initiating sepals and petals. The sty fis flower in $\mathrm{G}$ reveals severe overall reduction of SQUA expression at stage 5 . The arrow in $\mathrm{H}$ points to the hybridisation signal within the fourth whorl. (I) SQUA expression (arrows) is restricted to homeotically non-transformed regions of fis second whorl organs. Numbers indicate the respective floral whorls. b, bract. Bars represent $100 \mu \mathrm{m}$.
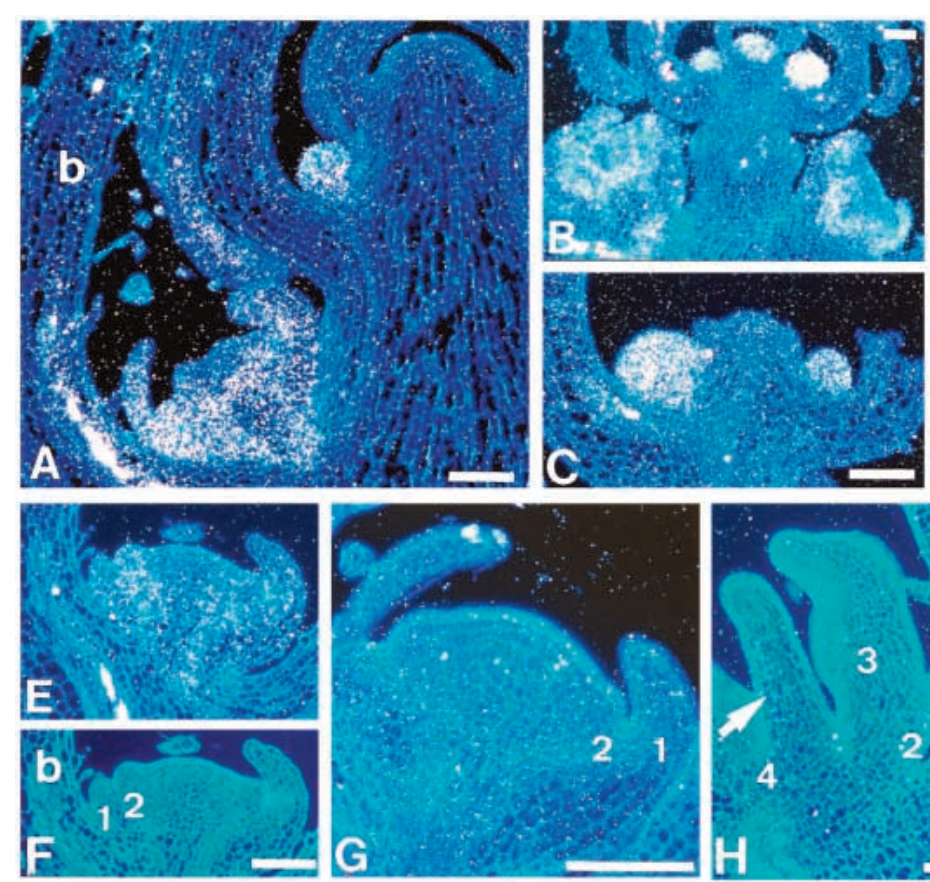

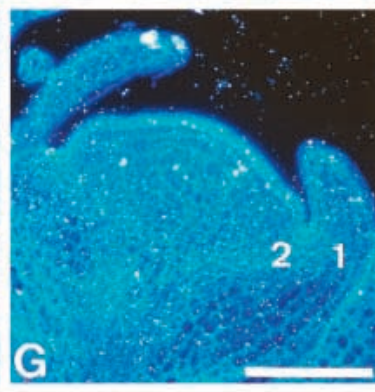

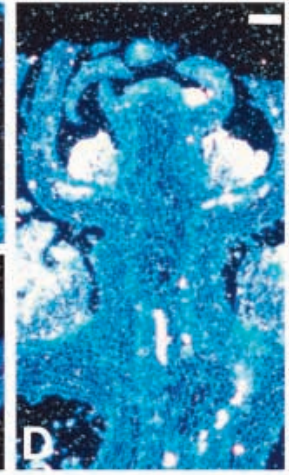
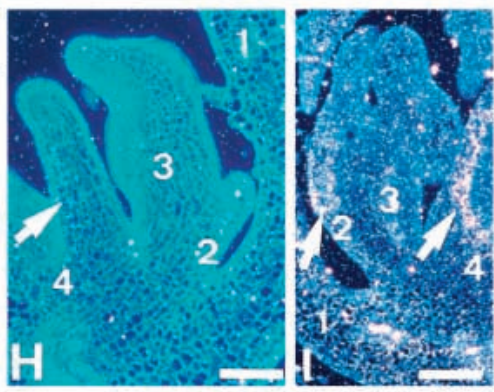
Fig. 7. In situ expression patterns of FIM in sty (A-E) and sty fis (F) mutant flowers. Longitudinal sections through floral meristems were hybridised with DIG-labelled antisense RNA probes, immunodetected with anti-DIG antibody coupled with alkaline phosphatase. In the bright-field photographs the hybridisation signal appears as a purple/brown precipitate. (A,B,D,E) Serial sections of floral buds of an intermediate sty mutant at stages 3 (A,D right), stage 5 (A,D left) and stage $6(B, E)$. The serial sections in $\mathrm{B}$ and $\mathrm{E}$ demonstrate ectopic expression of FIM within third whorl organ subdivisions (arrows). In strong sty flowers the FIM hybridisation signal is severely reduced at stage 3 (C) and it is absent in the central dome of the meristem. In the sty fis double mutant (F), FIM transcripts are hardly detectable in stage 3 and older floral meristems (arrows). b, bract; floral whorls are indicated by numbers. Bars represent $100 \mu \mathrm{m}$.
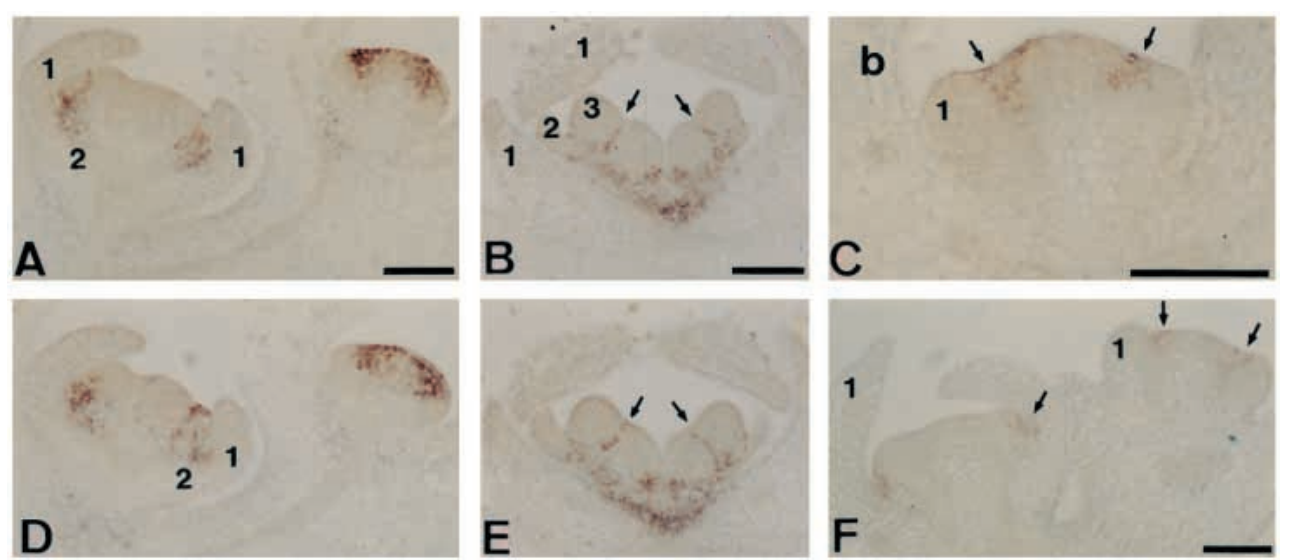

The expression pattern of FLORICAULA (FLO; Coen et al., 1990) was also determined and was found to be similar to that described above for SQUA (not shown).

\section{Expression of FIMBRIATA}

The spatial pattern of early FIM expression in wild-type, sty and fis flowers is similar except that the hybridisation signal seems to be patchy in sty (Fig. 7A,D). At stage 3 FIM transcripts appear in a ring internal to wild-type or mutant sepal primordia (Fig. 7A,C,D) with reduced signal intensity in strong sty flowers (Fig. 7C). Interestingly, FIM is expressed ectopically around the subdivisions of the third whorl organs, which are characteristic of sty flowers (Fig. 7B,E).

The level of FIM expression is markedly reduced in the sty fis double mutant. Already by late stage 3 FIM transcripts are hardly detectable and are only present at the boundary of the first and the second whorl and in a few cells, which may later separate the second and third whorls (Fig. 7F). At later stages only cells between sepals and the second whorl show weak FIM expression (Fig. 7F).

\section{Expression of the $\mathrm{B}$ organ identity genes $D E F$ and GLO}

Early $D E F$ transcription (Hantke et al., 1995; Zachgo et al., 1995 ) is not affected in sty flowers, except that it is slightly increased in the sepals and in the fourth whorl until stage 6 (Fig. 8F,G). In contrast, GLO expression (Tröbner et al., 1992) in sty flowers is reduced and patchy by stage 5 (Fig. 8C), and heterogeneity of the hybridisation signal by stage 4 indicates an early effect (Fig. 8B). Ectopic expression of the $G L O$ gene is sometimes observed in the sepals (not shown). Reduction of $G L O$ transcription in the second and third whorl organs of the sty mutant continues during later stages of development until it becomes restricted to petals and to the stamenoid tissue of the chimeric structure developing by the fusion of feminised stamens and the gynoecium (Fig. 8D). DEF transcripts after stage 6 are only detected in the tissues expressing $G L O$ (not shown). These observations suggest that early expression of $G L O$ is controlled directly or indirectly by $S T Y$ before the onset of the autoregulatory control in the second and third whorls that also affects $D E F$ transcription (Tröbner et al., 1992; Zachgo et al., 1995).
Similarly, in sty fis double mutant flowers, the $G L O$ hybridisation signal is heterogeneous at stage 4 (not shown). By late stage 5 , the signal is weak within regions facing the centre of the meristem and somewhat stronger in the region towards the first whorl. During later stages $G L O$ expression becomes further reduced and hardly detectable in the rudimentary second whorl organs (Fig. 8E).

\section{Expression of the $\mathrm{C}$ organ identity gene PLENA}

In the sty mutant early PLE expression in the centre of the flower, spanning the region that gives rise to stamens and carpels, is comparable to the pattern in wild type (Bradley et al., 1993; not shown). The intensity of the hybridisation signal does not seem to differ significantly from that in the wild type, but it is difficult to compare in situ expression patterns for subtle quantitative differences. Ectopic PLE expression in the initiating second whorl primordia by stage 5 is slightly above background and detectable by stage 6 (Fig. 9A). First whorl organs do not express PLE: undiluted emulsion combined with long exposure time did not reveal a signal above background (not shown). The spatial pattern of ectopic PLE expression in the second whorl is variable, but PLE transcripts were usually detected in sections through the marginal regions of differentiating second whorl organs even without stamenoid features (Fig. 9G,I). In the fourth whorl of sty flowers PLE is expressed in the style-like structures, which emerge from the placenta (Fig. 9I) and, similar to wild type, in the placenta, in developing ovules and in the tissue giving rise to the stigma (not shown).

$P L E$ expression was observed within the tip of upper leaves and in the carpelloid bracts of sty Ple- 888 double mutants where it is stronger than in Ple-888 plants (not shown).

In the fis mutant PLE is ectopically expressed in the abaxial second whorl organs at stage 6 (Fig. 9B). When antheroid structures develop, PLE transcripts are detectable in the same differentiated tissue as in wild-type third whorl organs, such as the vascular tissue, the epidermis of the style facing the gynoecium and the cells located between two antheroid locules. Epidermal cells of the adaxial corolla tube, facing the centre of the meristem and corresponding to the middle of second whorl organs, also show PLE transcription (Fig. 9). 
Fig. 8. In situ expression pattern of class B genes in wild-type (A) sty (B-D and F-G) and sty fis (E) flowers. Longitudinal sections of flowers were hybridised with antisense glo (A-E) and def (F-G) probes as indicated in the legend to Fig. 7. Wild-type (A) and sty (B) buds at stage 4 are shown side by side to demonstrate early reduction of $G L O$ expression in the mutant. Serial sections from sty buds at stage $5(C, F)$ and later $(D, G)$ were probed with glo (C,D) and def $(D, G)$ antisense probes for comparison of expression patterns. Arrows in D and $G$ point to fusion of carpelloid second and third whorl organs. Weak ectopic $D E F$ expression in the first whorl is visible in $\mathrm{F}$. The developmental
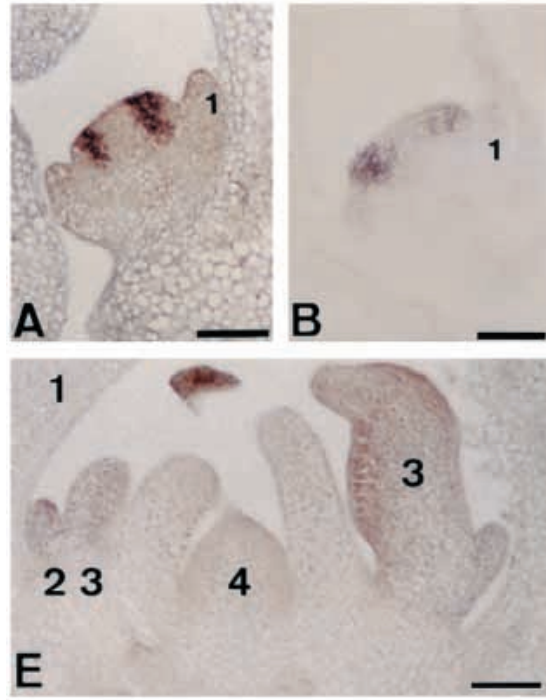
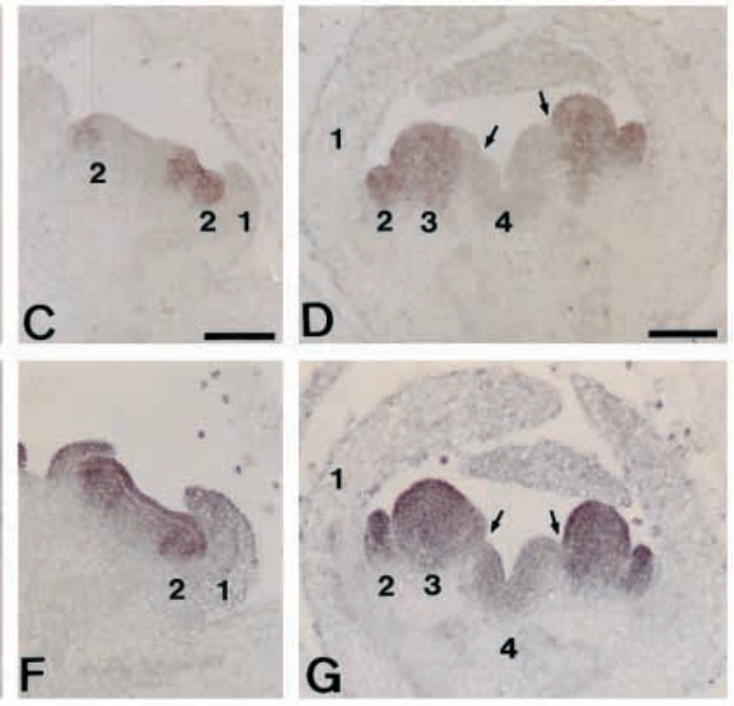

stage of the sty fis flower in E is comparable to the sty flowers in D,G. Floral whorls are indicated by numbers. Bars represent $100 \mu \mathrm{m}$.

Thus in the second whorl of sty and fis flowers the spatial pattern of ectopic PLE expression differs, corresponding to distinct regions that undergo homeotic transformation in mature organs of the mutants (Fig. 1A,F).

Ectopic PLE expression in the second whorl and in the epidermal cells of sepals in the first whorl is detectable in the sty fis double mutant by early stage 6 (Fig. 9C,D). In the second whorl PLE is either expressed in the entire initiating primordium or only in the cells facing the centre of the meristem. PLE transcripts are absent in those regions of the second whorl that appear as a rudimentary ridge in older flowers (Fig. 9E). PLE expression increases later in abaxial and lateral sepals and in developing second or third whorl stamens.

In summary, mutation in the STY and FIS genes leads to expansion of the expression domain of PLE towards the perianth organs of the flower. However, several lines of
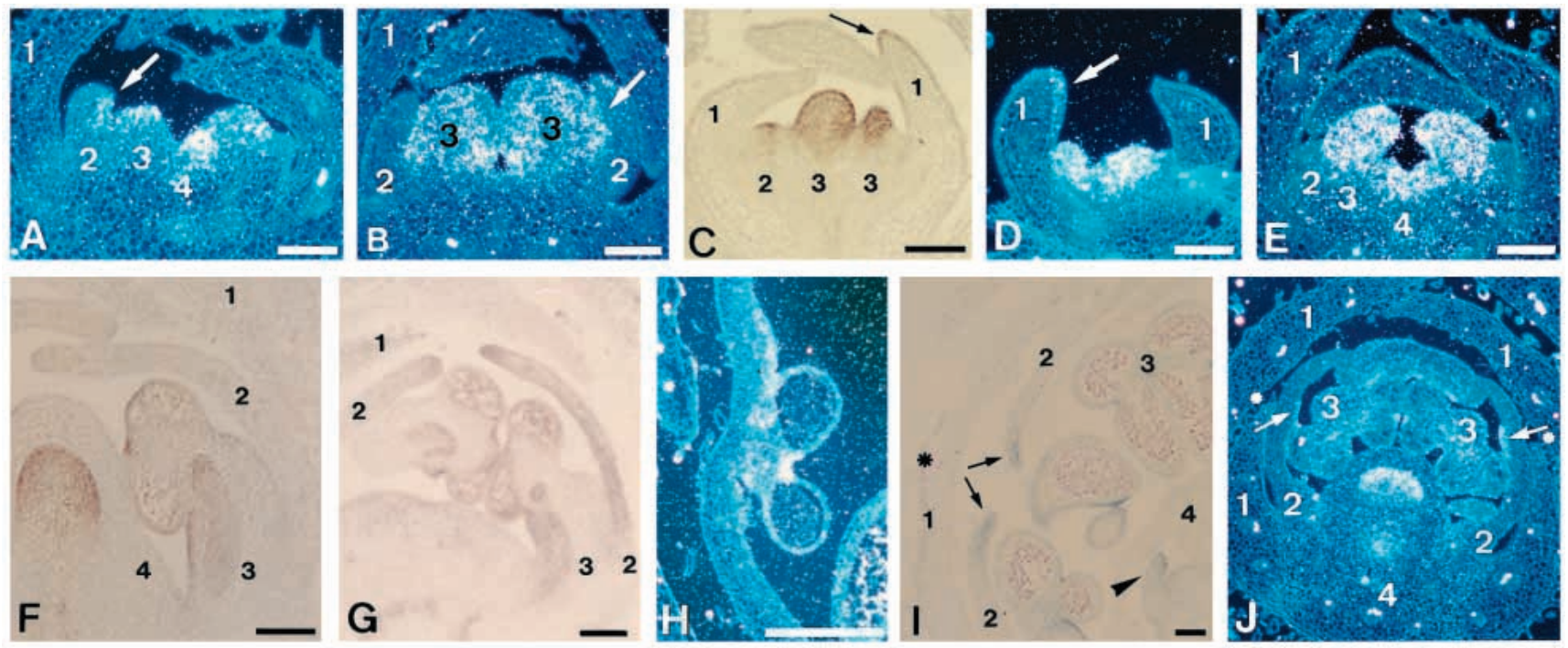

Fig. 9. In situ expression pattern of PLE in sty (A,G-I), fis (B,J) and sty fis (C-E) mutants. Longitudinal (A-H) and cross sections (I,J) of flowers were hybridised with the ${ }^{35} \mathrm{~S}$ - or DIG-labelled antisense ple probe and photographed as stated in the legends to Figs 6 and 7 . The section in I was in addition stained with fuchsin (red-coloured pollen). Arrows indicate ectopic PLE expression in the second whorl of stage 6 sty (A) and $f i s$ (B) buds as well as in the sepals of early stage 6 (C,D) sty fis flowers. (E) sty fis flower, stage 6. The spatial pattern of PLE expression in stamenoid organs of older mutant flowers is shown in the bottom row in comparison to that of a wild-type stamen (F). In G the PLE-expressing margin of the second whorl organ at the right is defined by sectioning through the filament of the neighbouring stamen. (H) The stamenoid second whorl organ of a strong sty flower. (I,J) Cross sections demonstrating the complementary pattern of hybridisation signals (arrows) obtained in the second whorl of sty (I) and fis (J) flowers. For orientation, the star in I marks the middle of a lateral sepal corresponding to the position of the margins of the second whorl organs, while the stars in $\mathrm{J}$ mark the margins of the lateral sepals corresponding to the middle position of the second whorl organs. The arrowhead in I points to a style like outgrowth within the fourth whorl, expressing PLE at its tip. Floral whorls are indicated by numbers. Bars represent $100 \mu \mathrm{m}$. 
evidence, in part summarised in Figure 10, suggest that PLE is not the primary target of $S T Y / F I S$ control. Firstly, early alteration of SQUA expression is independent of PLE in the sty fis ple triple mutant. Secondly, the ectopic PLE pattern appears later than changes in SQUA, FLO, FIM and $G L O$ expression during sty/fis flower development. Alterations in the spatial expression patterns of SQUA (and FLO) are also not correlated with ectopic expression of $P L E$, because overall reduction of $S Q U A$ transcripts in sty and sty fis mutant flowers occurs in the absence of PLE expression in the first whorl (Fig. 10D,F). In contrast, initiating Ple-888 first whorl organs already display ectopic PLE expression at stage 4 (Fig. 10C) without changes in the expression of SQUA (Fig. 10E), GLO (Fig. 10K) or FIM and FLO (not shown). In older Ple-888 flowers transcription of $S Q U A$ is reduced in restricted regions within the first whorl (Fig. 10I) that coincide with the ectopic presence of PLE transcripts (Fig. 10G). Thus, during later stages of organ differentiation $P L E$ negatively regulates $S Q U A$.

\section{DISCUSSION}

This work provides the first evidence that in Antirrhinum two genes, STYLOSA and FISTULATA, control homeotic gene expression, including the negative control of the $\mathrm{C}$-function gene PLE in the two outer whorls of the flower. In this feature and in the epistatic relation of ple to their mutants, STY and FIS resemble Arabidopsis A-function genes. However, several observations discussed below suggest that $P L E$ is not the immediate target of STY /FIS control. Although the synergistic effect of sty and fis indicates that the two genes control similar developmental event(s), it does not exclude the possibility that the target(s) are different. For simplicity the effects of STYIFIS are considered together in the discussion; the evidence for differences in STY and FIS target genes is beyond the scope of this report.

\section{The role of STY/FIS in the spatial control of perianth organ identity}

The C-function, represented by PLE, is necessary in the two inner whorls of the flower for the development of reproductive organs (Bradley et al., 1993). Reproductive organs in the perianth of sty fis mutants and the ectopically modified expression pattern of $P L E$ indicate that in the wild type the $S T Y$ and FIS genes together are responsible for the absence of PLE expression in the two outer whorls.

The influence of STY/FIS on PLE is possibly mediated by the meristem identity genes $F L O$ (Coen et al., 1990) and SQUA (Huijser et al., 1992). Dramatic changes in expression of FLO and SQUA during early sty fis flower development show that, in the wild type, maintenance of early SQUA and FLO expression is controlled by STY/FIS. In the sty fis mutant the loss of this (positive) control event precedes alterations of the PLE expression pattern. Thus, in the wild type, meristem identity genes may control exclusion of PLE from the outer whorls. This resembles the control relationships between class A and class $\mathrm{C}$ genes in Arabidopsis.

Interestingly, SQUA is similar to APl (Mandel et al., 1992), one of the class A genes in Arabidopsis that is necessary to negatively control the class $\mathrm{C}$ gene AGAMOUS (AG; Yanofsky et al., 1990) in the first and second floral whorls (Bowman et

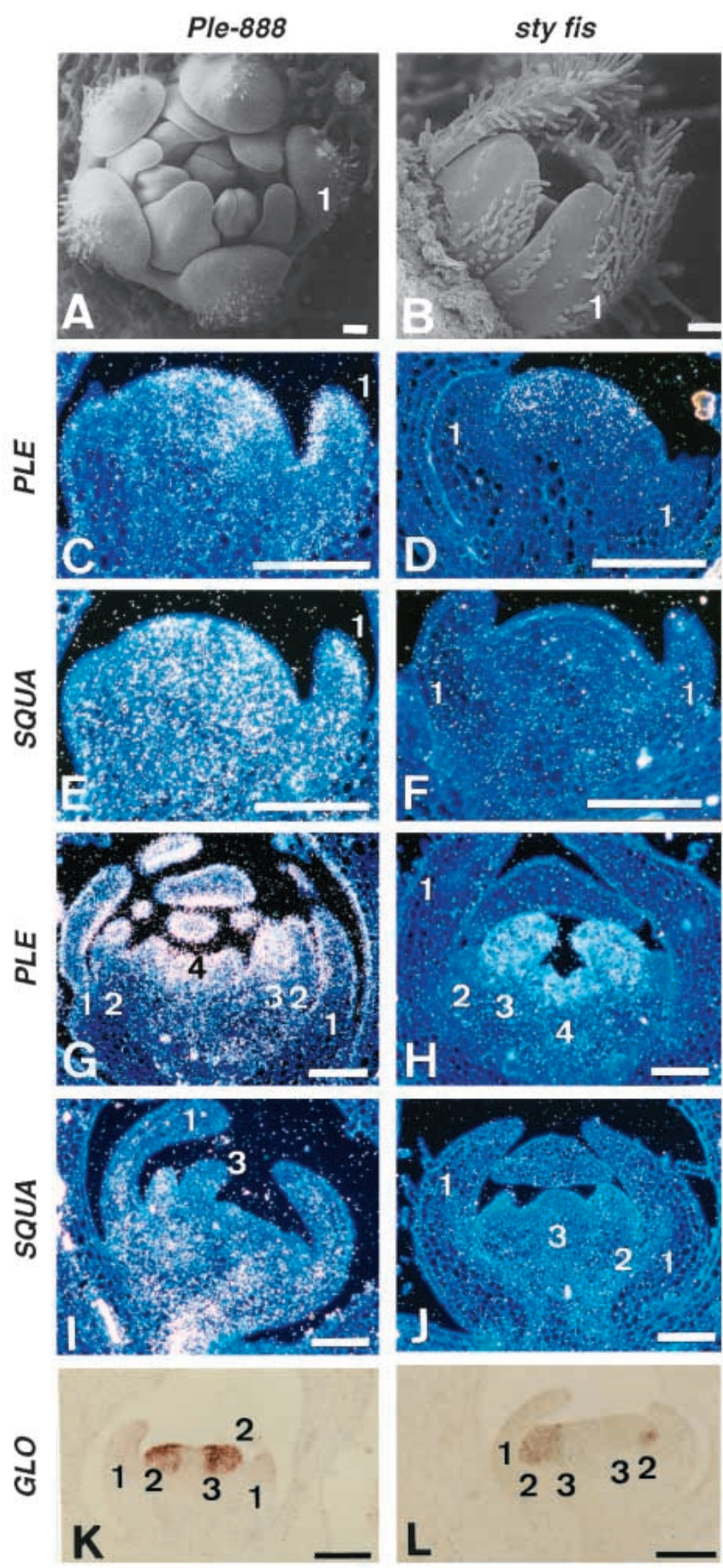

Fig. 10. Comparison of the in situ expression patterns of $P L E$, SQUA and GLO in Ple-888 and sty fis mutants. Genotypes are indicated above the panels and the probes used for hybridisation are shown at the left. (A,B) SEMs displaying severe organ transformation in the perianth of a Ple-888 flower (A) compared to the mild carpelloidy in the first whorl of a sty fis double mutant (B). The serial longitudinal sections for in situ hybridisation were prepared from flowers at stage $4(\mathrm{C}-\mathrm{F})$, stage $6(\mathrm{G}-\mathrm{J})$ and stage 5 $(\mathrm{K}, \mathrm{L})$ of development. Notice early ectopic PLE transcripts and strong SQUA expression in the Ple-888 flowers (C and G, respectively), compared to severe reduction of $S Q U A$ in the young sty fis flower $(\mathrm{H})$ in the absence of altered PLE expression pattern (D). Reduction of SQUA in the first whorl of Ple- 888 flowers (I) is detectable later in first whorl regions expressing PLE $(\mathrm{G})$. Numbers indicate the floral whorls. Bars represent $100 \mu \mathrm{m}$. 
al., 1993; Schultz and Haughn, 1993). The function of $S Q U A$ in the negative control of PLE is not manifested in the phenotype of squa mutants: its severe effect on floral meristem identity (revealed by indeterminate production of inflorescence shoots in the axils of bracts) and the fact that the SQUA function is occasionally by-passed in squa null mutants (revealed by development of more or less complete flowers; Huijser et al., 1992) could mask its role as a (cadastral) class A gene. Similarly, the strong apl-1 mutant, in spite of phenotypic differences to squa, displays inflorescence-like traits but does not reveal the cadastral role of $A P 1$ (GustafsonBrown et al., 1994) in the control of $A G$.

$A G$ negatively controls $A P I$. This is demonstrated in the wild-type third and fourth whorls and by decreased $A P I$ transcription due to ectopic $A G$ expression in the perianth of transgenic plants and ap2 mutants (Jack et al., 1997). Similarly, SQUA transcription gradually decreases in the $\mathrm{C}$ expression domain during early stages of development in the wild type and is reduced during late events of $\mathrm{C}$-dependent organogenesis in sty and fis mutants. Furthermore, in ple mutants SQUA transcription is maintained internal to the second whorl (Motte, unpublished). SQUA thus behaves like AP1. However, during early development, ectopic expression of PLE does not severely affect SQUA transcription in Ple-888 mutants reflecting, as shown in sty fis ple flowers, that SQUA is controlled by STYIFIS and not by PLE. The negative relation between SQUA as a class A gene and PLE as a single C class gene is apparent only during later stages of development.

\section{Control of floral organ specification}

$S T Y$ is involved in suppression of the C-function in upper parts of the plant as revealed by carpelloid features of upper leaves and bracts of the Ple-888 sty double mutant. The semidominant Ple-888 allele is only sufficient to confer carpelloidy to sepals and sometimes bracts and rarely affects upper leaf morphology (Bradley et al., 1993). This indicates that $S T Y$ already functions during the vegetative to floral transition.

However, initiation and specification of perianth organ development are not affected in sty and fis mutants, and prior to organ initiation early expression levels of $F L O$ and $S Q U A$ in fis, sty and sty fis mutants are similar to wild type. Assuming that the A-function is comparable between species and considering STY and FIS as its upstream regulators this could indicate that, along with $F I S$ and $S T Y$, other not yet identified components govern organogenesis in the perianth, or that residual functionality of the sty/fis alleles prevents detection of interference in this process. But it is also possible that in Antirrhinum the establishment of floral meristem identity is not easily separable from organ specification in the first whorl. If so, then meristem identity genes, as homeotic selectors, inevitably control the floral identity of organs in the flower. Consequently, a non-cadastral A function either does not exist or will escape detection in Antirrhinum. This agrees with observations suggesting that in Arabidopsis the role of APl and $A P 2$ in the specification of floral organ identity is inherent to their role in the establishment of floral meristem identity (Okamuro et al., 1997).

\section{STYIFIS control organogenesis in all floral whorls}

Once floral identity is established STYIFIS are necessary to maintain expression of SQUA and FLO in the perianth. Enhancement of the sty phenotype in the background of a weak flo mutation (which displays mild floral abnormalities without affecting floral transition; kindly provided by R. Carpenter) supports this notion (not shown). Alteration of B and C class organ identity gene expression in sty/fis mutants appears to be the consequence of this early event.

Retarded development of sty fis ple petals and feminisation of second and third whorl stamenoid organs in sty/fis mutants, relate to decreased expression of FIM and of class B homeotic genes (discussed below), where primarily $G L O$ and later $D E F$, are affected. The complex and temporally and spatially variable regulatory relationship between meristem identity genes, FIM and class B genes makes it difficult to identify the primary target(s) of STYIFIS. FLO is a candidate, because of its early control of both FIM and class B transcription (Hantke et al., 1995).

Style-like structures inside the carpels of sty and sty fis mutant flowers suggest a function of $S T Y$ in wild-type reproductive organ development. Mutation in ple is epistatic to sty with respect to the style-like structures, but overall enhanced expression of PLE in Ple-888 has no effect on stamen and little on carpel development (Bradley et al., 1993). Therefore, STY and FIS may control genes that interact with $P L E$, which may or may not belong to class $\mathrm{C}$, during reproductive organ development. Residual carpelloidy of fourth whorl organs and aberrant morphology of third whorl organs of ple mutant flowers point to additional class $\mathrm{C}$ gene functions.

\section{Control of initiation and growth of organs by STY is possibly mediated by FIMBRIATA}

Displacement of organ primordia causing fusion between floral organs, or a spiral rather than whorled organisation of mutant flowers indicate STY/FIS-dependent control of FIM as fim mutants display similar features. The control of organ growth by $S T Y$, as seen in subdivisions of third whorl primordia of sty mutants, arrested growth of second whorl primordia and reduction of organ number in the third whorl of the sty fis double mutant may also relate to early changes in the expression pattern of FIM in the mutants. FIM may be involved in the negative control of cell division (Ingram et al., 1997) and also in establishment of homeotic B and C class gene expression (Simon et al., 1994; Hantke et al., 1995; Ingram et al., 1997). The positive regulatory effect of FIM on class C genes is apparently circumvented in sty fis mutants.

Localised FIM expression represses growth, as evident, for example, from the presence of its transcript around second whorl primordia but not within the developing primordia. Subdivision of third whorl primordia in sty flowers may be promoted by this negative control of cell divisions in cells ectopically expressing FIM. In agreement with the proposed role of FIM, sty fim double mutant flowers do not display subdivisions of third whorl organs. Expression of B-function genes is necessary for this type of control, because subdivisions are absent in the sty def double mutant.

Reduced FIM expression in the sty fis double mutant affects expression of B-function genes, which also contribute to the control of cell division and/or elongation subsequent to initiation of organ primordia (Perbal et al., 1996). This could 
account, along with homeotic effects, for the severe arrest of organ development in the second whorl of sty fis flowers and also for reduced third whorl organ number. However, downregulation of FIM (or B) alone cannot be responsible for the failure to initiate organ primordia, because fim, def or fim def mutants do not display such features. We assume, therefore, that reduction of the FIM and B-functions combined with elevated C-function in sty and sty fis mutants cause these anomalies. Indeed, organ number in the third whorl is not affected in sty fis ple flowers, or in Ple-888 flowers (with ectopic PLE expression and with wild-type $S T Y$ function).

\section{STY and FIS control the C-function in different regions of wild-type petals}

The domains within wild-type petals where STY and FIS negatively control PLE, differ. Petals of sty mutants exhibit stamenoid features at their margins where they sometimes do not fuse and ectopic PLE expression is restricted to this marginal area. In contrast, fis second whorl organs display stamenoidy within the lobe and lateral fusions resulting in formation of the corolla tube. Ectopic PLE expression in fis petals is predominant in the lobe and within the middle of the tube-forming region. Concomitant loss of negative regulation of the C-function in the sty fis double mutant results in formation of morphologically nearly normal stamens in the second whorl or, as discussed above, in retarded growth of second whorl primordia. These observations suggest that, with regard to the developmental control of the C-function, wildtype second whorl organs are composed of two 'compartments': (1) a central (and in the mature flower, upper) region, controlled by the FIS gene and (2) a more lateral region controlled by STY. Such differences in the control of the central and lateral identity of organs are also documented in maize, based on studies with the recessive narrow sheath (ns) mutant (Scanlon et al., 1996). Developmental events (negatively) regulated by FIS and STY occur later in organogenesis than that controlled by $N S$, but both mechanisms reveal some similarity to compartmentalised wing formation in Drosophila, as discussed by Scanlon et al. (1996).

We are grateful to Drs Brendan Davies, George Haughn and Mark Wilkinson for discussions during preparation of this manuscript and for correction of the English. The criticism of the unknown reviewers that helped us to clarify our point of view is greatly acknowledged. We also thank Iris Heidmann and Heiner Meyer z.A. for their help in genetic experiments and maintenance of plants. This work was supported by grants from the Deutsche Forschungsgemeinschaft (SFB 243) and from the EEC/Biotechnology Programme (PTP Theme A1) to Z. Sch.-S.

\section{REFERENCES}

Bowman, J. L., Alvarez, J., Weigel, D., Meyerowitz, E. and Smyth, D. R. (1993). Control of flower development in Arabidopsis thaliana by APETALA1 and interacting genes. Development 119, 721-743.

Bradley, D., Carpenter, R., Sommer, H., Hartley, N. and Coen, E. (1993). Complementary floral homeotic phenotypes result from opposite orientations of a transposon at the plena locus of Antirrhinum. Cell 72, 85-95.

Carpenter, R. and Coen, E. S. (1990). Floral homeotic mutations produced by transposon-mutagenesis in Antirrhinum majus. Genes Dev. 4, 1483-1493.

Carpenter, R., Copsey, L., Vincent, C., Doyle, S., Magrath, R. and Coen, E. (1995). Control of flower development and phyllotaxy by meristem identity genes in Antirrhinum. Plant Cell 7, 2001-2011.
Coen, E. S. and Meyerowitz, E. M. (1991). The war of the whorls: genetic interactions controlling flower development. Nature 353, 31-37.

Coen, E. S., Romero, J. M., Doyle, S., Elliott, R., Murphy, G. and Carpenter, R. (1990). floricaula: a homeotic gene required for flower development in Antirrhinum majus. Cell 63, 1311-1322.

Davies, B. and Schwarz-Sommer, Z. (1994). Control of floral organ identity by homeotic MADS-box transcription factors. Results and Problems in Cell Differentiation. In Plant Promoters and Transcription Factors 20, 235-258.

Goodrich, J., Puangsomlee, P., Martin, M., Long, D., Meyerowitz, E. M. and Coupland, G. (1997). A Polycomb-group gene regulates homeotic gene expression in Arabidopsis. Nature 386, 44-51.

Gustafson-Brown, C., Savidge, B. and Yanofsky, M. F. (1994). Regulation of the Arabidopsis floral homeotic gene APETALA1. Cell 76, 131-143.

Hantke, S. S., Carpenter, R. and Coen, E. S. (1995). Expression of floricaula in single cell layers of periclinal chimeras activates downstream homeotic genes in all layers of floral meristems. Development 121, 27-35.

Haughn, G. W., Schultz, E. A. and Martinez-Zapater, J. M. (1995). The regulation of flowering in Arabidopsis thaliana - meristems, morphogenesis, and mutants. Can. J. Bot. 73, 959-981.

Haughn, G. W. and Somerville, C. R. (1988). Genetic control of morphogenesis in Arabidopsis. Dev. Genet. 9, 73-89.

Huijser, P., Klein, J., Lönnig, W. -E., Meijer, H., Saedler, H. and Sommer, H. (1992). Bractomania, an inflorescence anomaly, is caused by the loss of function of the MADS-box gene squamosa in Antirrhinum majus. EMBO J. 11, 1239-1249.

Ingram, C. G., Doyle, S. D., Carpenter, R., Schultz, E. A., Simon, R. and Coen, E. S. (1997). Dual role for fimbriata in regulating floral homeotic genes and cell division in Antirrhinum. EMBO J. (in press).

Jack, T., Sieburth, L. and Meyerowitz, M. (1997). Targeted misexpression of AGAMOUS in whorl 2 of Arabidopsis flowers. Plant J. 11, 825-839.

Jofuku, K. D., den Boer, B. G. W., Van Montagu, M. and Okamuro, J. K. (1994). Control of Arabidopsis flower and seed development by the homeotic gene APETALA2. Plant Cell 6, 1211-1225.

Liu, Z. and Meyerowitz, E. M. (1995). LEUNIG regulates AGAMOUS expression in Arabidopsis flowers. Development 121, 975-991.

Lönnig, W. E. and Saedler, H. (1994). The homeotic Macho mutant of Antirrhinum majus reverts to wild-type or mutates to the homeotic plena phenotype. Mol. Gen. Genet. 245, 636-643.

Mandel, M. A., Gustafson-Brown, C., Savidge, B. and Yanofsky, M. F. (1992). Molecular characterization of the Arabidopsis floral homeotic gene APETALA1. Nature 360, 273-277.

Okamuro, J. K., den Boer, B. G. W. and Jofuku, K. D. (1993). Regulation of Arabidopsis flower development. Plant Cell 5, 1183-1193.

Okamuro, J. K., Szeto, W., Lotys-Prass, C. and Jofuku, K. D. (1997). Photo and hormonal control of meristem identity in the Arabidopsis flower mutants apetala2 and apetala1. Plant Cell 9, 37-47.

Perbal, M. -C., Haughn, G., Saedler, H. and Schwarz-Sommer, Z. (1996). Non-cell-autonomous function of the Antirrhinum floral homeotic proteins DEFICIENS and GLOBOSA is exerted by their polar cell-to-cell trafficking. Development 122, 3433-3441.

Samach, A., Kohalmi, S. E., Motte, P., Datla, R. and Haughn, G. W. (1997) Divergence of function and regulation of class B floral organ identity genes. Plant Cell 9, 559-570.

Scanlon, M. J., Scheeberger, R. G. and Freeling, M. (1996). The maize mutant narrow sheath fails to establish leaf margin identity in a meristematic domain. Development 122, 1683-1691.

Schultz, E. A. and Haughn, G. W. (1993). Genetic analysis of the floral initiation process (FLIP) in Arabidopsis. Development 119, 745-765.

Schwarz-Sommer, Z., Hue, I., Huijser, P., Flor, P. J., Hansen, R., Tetens, F., Lönnig, W. -E., Saedler, H. and Sommer, H. (1992). Characterization of the Antirrhinum floral homeotic MADS-box gene deficiens: evidence for DNA binding and autoregulation of its persistent expression throughout flower development. EMBO J. 11, 251-263.

Schwarz-Sommer, Z., Huijser, P., Nacken, W., Saedler, H. and Sommer, H. (1990). Genetic control of flower development by homeotic genes in Antirrhinum majus. Science 250, 931-936.

Simon, R., Carpenter, R., Doyle, S. and Coen, E. (1994). Fimbriata controls flower development by mediating between meristem and organ identity genes. Cell 78, 99-107.

Sommer, H., Beltran, J. P., Huijser, P., Pape, H., Lönnig, W. E., Saedler, H. and Schwarz-Sommer, Z. (1990). Deficiens, a homeotic gene involved in the control of flower morphogenesis in Antirrhinum majus: the protein shows homology to transcription factors. EMBO J. 9, 605-613. 
Stubbe, H. (1974). Neue Mutanten von Antirrhinum majus L. Kulturpflanze. XXII, 189-213.

Tröbner, W., Ramirez, L., Motte, P., Hue, I., Huijser, P., Lönnig, W. -E., Saedler, H., Sommer, H. and Schwarz-Sommer, Z. (1992). GLOBOSA: a homeotic gene which interacts with DEFICIENS in the control of Antirrhinum floral organogenesis. EMBO J. 11, 4693-4704.

Tsuchimoto, S., van der Krol, A. R. and Chua, N. H. (1993). Ectopic expression of pMADS3 in transgenic petunia phenocopies the petunia blind mutant. Plant Cell 5, 843-853.
Weigel, D. and Meyerowitz, E. M. (1994). The ABCs of floral homeotic genes. Cell 78, 203-209.

Yanofsky, M. F., Ma, H., Bowman, J. L., Drews, G. N., Feldmann, K. A. and Meyerowitz, E. M. (1990). The protein encoded by the Arabidopsis homeotic gene agamous resembles transcription factors. Nature 346, 35-39.

Zachgo, S., de Andrade Silva, E., Motte, P., Tröbner, W., Saedler, H. and Schwarz-Sommer, Z. (1995). Functional analysis of the Antirrhinum floral homeotic DEFICIENS gene in vivo and in vitro by using a temperaturesensitive mutant. Development 121, 2861-2875. 